\title{
Nonlinear Vibration Analysis of Tubing Strings in Underground Gas Storage Using Multiscale Wavelet Transform
}

\author{
Hang Yan, ${ }^{1}$ Yifei Yan $D^{2},{ }^{2}$ and Xiangzhen Yan $^{1}$ \\ ${ }^{1}$ College of Pipeline and Civil Engineering, China University of Petroleum, Qingdao 266580, China \\ ${ }^{2}$ College of Mechanical and Electronic Engineering, China University of Petroleum, Qingdao 266580, China
}

Correspondence should be addressed to Yifei Yan; 20180056@upc.edu.cn

Received 18 November 2018; Revised 4 February 2019; Accepted 20 March 2019; Published 6 May 2019

Academic Editor: Ivo Caliò

Copyright (c) 2019 Hang Yan et al. This is an open access article distributed under the Creative Commons Attribution License, which permits unrestricted use, distribution, and reproduction in any medium, provided the original work is properly cited.

The tubing string exposed to transient flow may undergo nonlinear vibration due to sudden change in pressure in conveying gas. But, the drag on such structures often leads to fatigue failure of the strings that may significantly affect the vibrations through the combined effects of the first sections of gas injection, annulus pressure, the inclined structures, and the large transient flow component. In this paper, the nonlinear vibration analysis of tubing strings in underground gas storage using the multiscale wavelet transform has been studied. The vibration characteristics of strings in the steady gas injection process have been analyzed by numerical simulation. Results of the calculation model are compared to numerical ones reported previously, and the excellent agreement is obtained. The nonlinear vibration experiment of strings in the gas injection process has been studied for discussing the change rules of the string pressure, the wall velocity, and the amplitude in the gas injection process. The results show that the near-injection port section and the inclined section of strings are the high-incidence areas of nonlinear vibration of strings in underground gas storage. We also find that significant alteration of the dynamics is due to low-frequency pressure fluctuation forces on the tubing strings.

\section{Introduction}

The safety of underground gas storage pipe strings has been a prominent subject of research for many years, especially in the complex geological conditions of China's gas storage, which results in deep burial of the gas storage well. First, the underground structure will face cyclical changes in temperature and pressure during injection and production $[1,2]$. When a change occurs in a string system, a transient flow in strings will be generated. Then, the sudden change in gas velocity causes a pressure wave to propagate within the strings. Compared to the steady state, the pressures can reach excessive values, which can easily induce a vibration of the injection and production well strings and can even lead to gas leakage, failure of the packer, fatigue failure of the strings, and so on [3-5].

The large majority of existing studies focus on string mechanics in a variety of conditions: rigid or flexible, vertical or inclined structure, and steady or transient flow $[6,7]$.
However, most of the first sections of gas injection and inclined structures described above have large fluctuations in pressure inside the tube under the action of turbulence. First, the mechanical behavior of strings has an important effect on the response of the string system during dynamic loading. The rheological behavior of continuous or natural gas viscoelasticity results in large fluctuations in the pressure within the tubing string and acts on the delayed expansion and circumferential strain of the pipe wall. Second, the vertical structure is not partially perpendicular to the flow, while the curved structure undergoes a change in flow direction from its angle of free flow, which changes the flow characteristics of the injected or produced natural gas and the structural correlation.

As the first to study the vibration of gas storage strings, Stefan and Cunha enriched and perfected the classical, established system of rod string mechanics calculations [8]. Yang et al. analyzed the mechanism of string vibrations induced by natural gas in high production gas wells, 
obtained the excitation force of natural gas to the string, and used finite element software to achieve the vibration characteristic analysis and dynamic analysis of the string [9]. On the basis of their predecessors' research, Dou and Leiqi studied the dynamic problem of the vibration of gas well strings by theoretical derivation or finite element simulation and obtained the change rule of the vibration of strings as induced by gas [10]. The above research lays a solid foundation for the development of this paper, but it does not fully consider the special operation conditions of injection and production cycles in gas storage, which leads to the conclusion that the research on nonlinear vibration of injection and production strings is not enough. At this point, however, there is a lack of research results that demonstrate the effect of pressure fluctuations caused by flow on the tubing string of an elongated cylinder and that determine the physical mechanism by which vibration occurs. One might want to know how pressure fluctuations caused by bending in normal flow affect the vibration spectrum and, further, how the amplitude of vibration might be affected.

The purpose of this paper is to establish a nonlinear vibrational mechanical model of the tubing string, taking into account the viscoelastic effect of the annulus liquid, in particular, based on Rayleigh-Love rod theory and the theoretical formula of the tubing string mechanics, which explain the nonlinear vibration effect of the tubing string of the $i$-th stage of the gas storage well. We will also use the multiscale wavelet transformation to analyze the small amplitude vibration of the gas storage string caused by pressure fluctuations to identify the physical mechanism in the tubing string vibration. This type of model was originally designed to represent the large deformation elastic characteristics behind the pile structure $[11,12]$, and they have been shown to give some of the same characteristics as the vibration characteristics of the pipe. In the application of wavelet nonlinearity, the work of Farge and Schneider and Liu et al. proves that the wavelet function has good locality in both time and frequency domains when solving nonlinear dynamic equations $[13,14]$. To improve solution accuracy and efficiency, the above work further proves that many features of the nonlinear vibration dynamics of the tubing string can be explained by solution analysis of the multiscale wavelet transformation.

In addition, the nonlinear vibration mechanics model of the gas storage well string and the numerical solution of its mathematical equation are introduced in Section 2. Then, based on the results of numerical simulations, the effect of flow-induced pressure fluctuations on the tubing string is discussed in Section 3. Finally, in Section 4, the vibration experimental results of the gas storage well string are studied and the results of the nonlinear vibration characteristics of the gas storage well string are verified.

\section{Modeling and Solution}

2.1. Nonlinear Mechanical Model of String Vibration. Based on the theory of elasticity and string mechanics, a mechanical analytic model of a well string for gas storage is established, as shown in Figure 1. To facilitate numerical analysis, it is assumed that the downhole string is a long straight rod with isotropic, uniform continuous linear elastic characteristics, and it is regarded as a single unit evenly divided into parts. In Figure 1, it also gives a mechanical vibration analysis model for the $i$-th section of the well string of underground gas storage in the gas injection process.

A tube-casing annulus is filled with protection fluid, which reduces the reservoir pressure that the casing head or packer bears and lowers the pressure difference between the tubing and annulus. Due to its excellent shear stability and viscosity, the multicomponent filling fluid can produce a liquid spring effect. Therefore, the variable stiffness spring structure is added to this model.

As shown in Figure 1, under initial conditions, the pressure inside the tube is $f_{0}$ and the volume of liquid is $v$ and when the string is subjected to continuous excitation and radial displacement occurs, the annulus pressure becomes $f_{1}$ and the volume change of liquid is $\Delta v$. Assuming that the temperature in the annulus is constant, the spring effect force of the annulus protection fluid using hydraulic spring stiffness and an elastic force model [15] is

$$
\Delta F=\frac{\Delta f}{\Delta v} \frac{A_{i}^{2}}{v} \Delta x=k \Delta x,
$$

where $\Delta f=f_{1}-f_{0}$, with the volume of liquid $v$ increasing or decreasing; thereby, the stiffness of the spring $k$ is changed. When $\Delta v \longrightarrow 0, k$ is

$$
k=\frac{d f}{d x}=\frac{-d p A_{i}^{2}}{\left(d v / A_{i}\right)}=\beta \frac{A_{i}^{2}}{v_{i}},
$$

where $k$ is the stiffness of the liquid spring, which is directly proportional to the bulk elastic modulus and the crosssectional area.

2.2. Nonlinear Vibration Calculation Model of String. Based on Rayleigh-Love rod theory and string mechanics, the nonlinear vibration equation of the $i$-th segment of the injection production gas storage string can be expressed as

$$
\begin{gathered}
E_{i} A_{i} \frac{\partial^{2} u_{i}}{\partial z^{2}}+A_{i} \delta_{i} \frac{\partial^{3} u_{i}}{\partial z^{2} \partial t}-\rho A\left(\frac{\partial^{2} u_{i}}{\partial t^{2}}-v_{i}^{2}\left(r_{i}^{2}-r_{i}^{\prime 2}\right) \frac{\partial^{4} u_{i}}{\partial z^{2} \partial t^{2}}\right) \\
-\Delta f-f_{i}=0
\end{gathered}
$$

where $u_{i}=u_{i}(z, t)$ denotes the longitudinal displacement of the $i$-th segment of the downhole string. Using $c_{i}$ to denote the longitudinal shear complex stiffness in the unit length direction of the downhole drill string contact surface, $f_{i}$ and $A_{i}$ can be expressed as

$$
\begin{aligned}
& f_{i}=c_{i} u_{i}(z, t), \\
& A_{i}=\pi\left(r_{i}^{2}-r_{i}^{\prime 2}\right) .
\end{aligned}
$$

The displacement on the two sides of the interface between the adjacent microelements of the downhole string must satisfy the continuity condition as follows: 

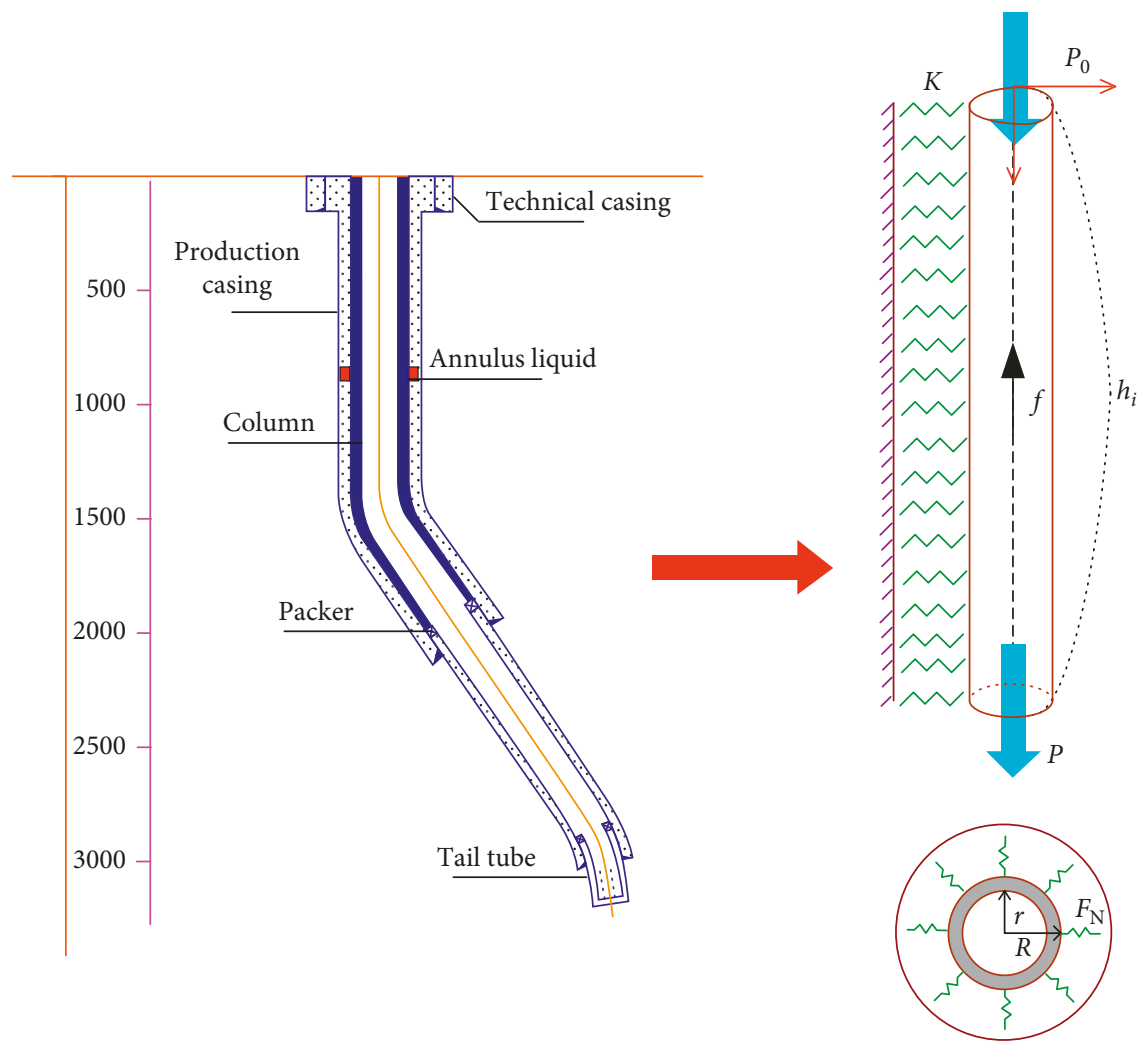

Figure 1: Nonlinear vibration mechanical model of a gas storage well string in a depleted oil and gas reservoir.

$$
\left\{\begin{array}{l}
\left.u_{i-1}(z, t)\right|_{z=h_{i-1}}=\left.u_{i}(z, t)\right|_{z=h_{i}}, \\
\left.u_{i}(z, t)\right|_{z=h_{i}}=\left.u_{i}(z, t)\right|_{z=h_{i+1}} .
\end{array}\right.
$$

Setting $\varphi_{i}(z, t)=E_{i}\left(\partial^{2} u_{i} / \partial z^{2}\right)+\delta_{i}\left(\partial^{3} u_{i} / \partial z^{2} \partial t\right)+\rho_{i} v_{i}^{2}$ $\left(r_{i}^{2}-r_{i}^{\prime 2}\right)\left(\partial^{4} u_{i} / \partial z^{2} \partial t^{2}\right)$, the force on the cross section must satisfy the continuity condition as follows:

$$
\left\{\begin{array}{l}
\left.\varphi_{i-1}(z, t)\right|_{z=h_{i-1}}=\left.\varphi_{i}(z, t)\right|_{z=h_{i}}, \\
\left.\varphi_{i}(z, t)\right|_{z=h_{i}}=\left.\varphi_{i}(z, t)\right|_{z=h_{i+1}}
\end{array}\right.
$$

2.3. Solution of the Model. Compared with the Fourier transform, the wavelet function has good locality in both the time and frequency domains when solving nonlinear dynamic equations, which can improve calculation accuracy and efficiency. Therefore, in this paper, the nonlinear vibration equation of the injection string and production well is numerically solved by using the wavelet function. The formula of the wavelet function is as follows:

$$
\begin{aligned}
w(a, b) & =\left\langle f(t), \psi_{a, b}(t)\right\rangle=\frac{1}{\sqrt{a}} \int f(t) \psi^{*}\left(\frac{t-b}{a}\right) d t, \\
\psi(t) & =e^{-(1 / 2) t^{2}} e^{j \omega_{0} t},
\end{aligned}
$$

where $w_{0}$ denotes the center frequency of the wavelet.

In setting up sustained stimulation of the downhole string, the initial displacement and speed of the $i$-th segment of the downhole string are both equal to 0 . Combining this with equations (3) and (7), the following equation is obtained:

$$
\begin{aligned}
& \left(E A_{i} t^{2}+2 A_{i} \delta_{i} t+\frac{2 \rho_{i} A_{i}^{2} v_{i}^{2}}{\pi}\right) \frac{\partial^{2} U_{i}}{\partial z^{2}}-\left(2 \rho_{i}+C_{k} t^{2}\right) U_{i} \\
& -\frac{k_{i} \Delta x}{A_{i}} t^{2}=0
\end{aligned}
$$

where $U_{i}=U_{i}(z, s)$ is the wavelet transform formula of $u_{i}(z, t)$.

To simplify the solution, set

$$
\begin{aligned}
& \alpha=E A_{i} t^{2}+3 A_{i} \delta_{i} t+\frac{6 \rho_{i} A_{i}^{2} v_{i}^{2}}{\pi}, \\
& \beta=6 \rho_{i}+C_{i} t^{2}, \\
& \xi_{i}=\frac{k_{i} \Delta x}{A_{i}} t^{2} .
\end{aligned}
$$

Then, equation (9) can be simplified to

$$
\alpha \frac{\partial^{2} U_{i}}{\partial z^{2}}-\beta U_{i}-\xi_{i}=0
$$

Thus, the solution of equation (11) is

$$
U_{i}(z, s)=C_{1} e^{r_{1}}+C_{2} e^{r_{2}},
$$


where $r_{1}=\left(\beta+\sqrt{\beta^{2}-2 \alpha \delta} / 2 \alpha\right)$ and $r_{1}=\left(\beta-\sqrt{\beta^{2}-2 \alpha \delta} / 2 \alpha\right)$. It is known from equations (7) and (9) that $\beta-2 \alpha \delta \geq 0$. Therefore, the equation is solvable.

As the underground gas storage has a built-in depleted gas reservoir, the following reasonable assumptions can be made: the stratum of the gas storage can be regarded as infinite, there is only the residual natural gas in the depleted gas reservoir, the nature of injected natural gas is the same as that of residual natural gas, and the initial reservoir pressure of the depleted gas reservoir is $p_{j, 0}$. Therefore, the process of gas injection from the wellbore can be regarded as a plane radial flow of fluid into the formation. Therefore, the mathematical and physical equations of the gas injection process [17] can be written in the following form:

$$
\begin{cases}\frac{\partial^{2} p}{\partial r_{\mathrm{c}}^{2}}+\frac{1}{r} \frac{\partial p}{\partial r_{\mathrm{c}}}=\frac{1}{\chi} \frac{\partial p}{\partial t}, & \left.p\right|_{t=0}=p_{j, 0}, \\ \left.\frac{\partial p}{\partial r_{\mathrm{c}}}\right|_{r=r_{\mathrm{c}}}=\frac{G_{\mathrm{g} i} \mu}{2 \pi K h r_{\mathrm{c}}}, & \left.p\right|_{r_{\mathrm{c}} \longrightarrow \infty}=p_{j, 0} .\end{cases}
$$

Combined with equation (13), the relationship between formation pressure and time $t$ and radius $r$ after gas injection is obtained as follows [9]:

$$
q_{i}(z, t)=P_{0}+\frac{G_{\mathrm{g} i} \mu}{4 \pi K h}\left[-E_{i}\left(-\frac{z^{2}}{4 \chi t}\right)\right] .
$$

Setting $F_{i}(z, t)=\varphi(z, t) A_{i}$, the vibration of the bottom string should meet the following requirements:

$$
\begin{aligned}
\left.F_{i}(z, t)\right|_{z=0}+q_{i}(z, t) & =0, \\
\left.U_{i}(z, s)\right|_{h} & =0 .
\end{aligned}
$$

Combining equations (15) and (16) into (12), we obtain the following equations:

$$
\begin{gathered}
\left(r_{2} m+r_{1} n\right) C_{1}+\left(r_{2} m-r_{1} n\right) C_{2}=\frac{\alpha^{2} q_{i}(z, s)}{\beta A_{i}}, \\
C_{1} e^{r_{1}}+C_{2} e^{r_{2}}=0
\end{gathered}
$$

Among them, wavelet transform is carried out: $q_{i}(z, s)=(1 / \sqrt{a}) \int q(t) \psi((t-b) / a) d t$.

$$
\begin{gathered}
m=E_{i}+\delta_{i} t, \\
n=\frac{\rho_{i} v_{i}^{2} A_{i} t^{2}}{\pi} .
\end{gathered}
$$

Combining equations (19), (20), and (18), $C_{1}$ and $C_{2}$ are calculated as follows:

$$
\begin{aligned}
& C_{1}=\frac{\alpha^{2} q_{i}(z, s)}{\left[r_{2} m\left(e^{r_{2}}-e^{r_{1}}\right)+r_{1} n\left(e^{r_{2}}+e^{r_{1}}\right)\right] \beta A_{i}}, \\
& C_{2}=-\frac{\alpha^{2} q_{i}(z, s)}{\left[r_{2} m\left(e^{r_{2}}-e^{r_{1}}\right)+r_{1} n\left(e^{r_{2}}+e^{r_{1}}\right)\right] \beta A_{i}} .
\end{aligned}
$$

Vibration displacement of the downhole completion string at $t=t_{i}$ is as follows:

$$
u_{i}(z, s)=\frac{\alpha^{2}\left(e^{r_{1}}-e^{r_{2}}\right) q_{i}(z, s)}{\left[r_{2} m\left(e^{r_{2}}-e^{r_{1}}\right)+r_{1} n\left(e^{r_{2}}+e^{r_{1}}\right)\right] \beta A_{i}} .
$$

The corresponding vibration frequency-domain formula is as follows:

$$
u_{i}(z, i w)=\frac{\alpha^{2}\left(e^{r_{1}}-e^{r_{2}}\right) q_{i}(z, i w)}{\left[r_{2} m\left(e^{r_{2}}-e^{r_{1}}\right)+r_{1} n\left(e^{r_{2}}+e^{r_{1}}\right)\right] \beta A_{i}} .
$$

To solve the natural frequency of the wellbore string, formula (3) is dimensionless:

$$
\frac{\partial^{2} w_{i}}{\partial \xi^{2}}+\tau_{i} \frac{\partial^{3} w_{i}}{\partial \xi^{2} \partial \eta}-\frac{\partial^{2} w_{i}}{\partial \eta^{2}}-\gamma_{i} \frac{\partial^{4} w_{i}}{\partial \xi^{2} \partial \eta^{2}}-\left(\Delta f+f_{i}\right) w_{i}=0,
$$

where $w_{i}=\left(u_{i} / h\right), \xi=(z / h)$, and $\eta=(t / h \sqrt{E / \rho})$.

The multistep frequency value of the pipe string can be obtained by formula (24), wherein the first and second frequency values of the strings are as follows:

$$
\begin{gathered}
w_{1}=\frac{1}{h^{2}} \sqrt{\frac{c \pi E\left(R_{i}^{2}-r_{i}^{2}\right)}{\rho}\left(\frac{n_{2}-\sqrt{n_{2}^{2}-4 n_{1} n_{3}}}{2 n_{1}}\right),} \\
w_{2}=\frac{1}{h^{2}} \sqrt{\frac{c \pi E\left(R_{i}^{2}-r_{i}^{2}\right)}{\rho}\left(\frac{n_{2}+\sqrt{n_{2}^{2}-4 n_{1} n_{3}}}{2 n_{1}}\right)}, \\
\left\{\begin{array}{l}
n_{1}=\left(1+4 \gamma_{i} \pi^{2}\right)\left(1+\gamma_{i} \pi^{2}\right), \\
n_{2}=\left(1+4 \gamma_{i} \pi^{2}\right)\left(\left(\Delta f+f_{i}\right)+\gamma_{i} \pi^{2}\right) \\
+\left(1+4 \gamma_{i} \pi^{2}\right)\left(\left(\Delta f+f_{i}\right)+\gamma_{i} \pi^{2}\right)-4 \gamma_{i} \pi^{2}, \\
n_{3}=\left(\left(\Delta f+f_{i}\right)+4 \pi^{2}\right)\left(\left(\Delta f+f_{i}\right)+\pi^{2}\right) .
\end{array}\right.
\end{gathered}
$$

\section{Engineering Example Analysis}

3.1. Field Data. The well group of the J03 block of gas storage in depleted oil and gas reservoirs is located in southern China. It is diverted from the original main production well and has a good natural sealing structure. After completion, it will meet the urgent demand for the gas storage season and safety peak shaving capacity from long distance pipelines, such as the Shan-Jing gas transmission pipelines, the second Shan-Jing gas transmission pipeline, and the west-east gas transmission pipelines. Therefore, the demand for the design and safe operation of gas storage is relatively high. This paper mainly analyzes the J03-H1 gas storage well.

3.2. Finite Element Model. By means of ANSYS, the nonlinear vibration finite element analysis model of gas storage well strings in depleted oil and gas reservoirs in the gas injection process is established (shown in Figure 2(a)) based on working field parameters. The model adopts the tube element Pipe288 for simulation, which has the properties of tension, bending, and torsion, and each node of the element 
has 6 degrees of freedom. The mesh sizes (shown in Figure 2(b)) were refined in a sweep mode with 10 elements around the pipe circumference, and elements along its axis were finally adopted with a distance of $0.3 \mathrm{~m}$. The element number is 20000, and node number is 20020. Numerical integration is based on the Newton-Cotes integral method. To simulate the viscoelastic effect of protection fluid in the tube-casing annulus, the nonlinear spring element Combin39 is added to both ends of each tube element of the vibration model of the injection and production string, and the direction of the addition includes the axial direction, the horizontal direction, and the vertical direction. The finite element model of the injection and production string is shown in Figure 2. It is assumed that the element Combin39 is only allowed to have axial deformation. The string is made of $\varnothing 114.3 \times 14.22$ steel pipe, and its basic parameters are shown in Table 1.

3.3. Analysis of the Inherent Characteristics of String. To verify the accuracy and precision of the nonlinear vibration calculation model of the gas storage well string, the author uses MATLAB to compile the calculation model and then uses the calculation model to simulate a certain production condition of well J03-H1 in the gas storage. The production conditions of well J03-H1 are shown in Table 2. Meanwhile, the multiperiodic harmonic response analysis of the injection string under the same production condition is done by using the three-dimensional finite element model. Numerical simulation conditions are set as follows: the injection pressure $35 \mathrm{MPa}$, the axial force of the string $20 \mathrm{kN}$, the phase angle 0 , and the load frequency range $0 \sim 0.5 \mathrm{~Hz}$. String frequency calculated by the model in this paper is compared with that calculated by the finite element model, as shown in Figure 3.

A comparison of the results calculated by the model in this paper without considering the annulus constraint (NAP), the results calculated by the model in this paper considering the annulus constraint (CAP), and the results of harmonic response analysis (N-S) are shown in Figure 3. From the comparison of the calculation results of the string frequency, it is found that, for a string with a certain length, the calculation value of the natural frequency considering the annulus pressure constraint is greater than that without considering the annulus pressure constraint, and it is close to the finite element analysis results. When the length of the string is approximately $400 \mathrm{~m}$, the natural frequency value without considering the annulus pressure constraint is $0.378 \times 10^{-1} \mathrm{~Hz}$, and the natural frequency value considering the annulus pressure constraint is $0.391 \times 10^{-1} \mathrm{~Hz}$, while the numerical value is $0.402 \times 10^{-1} \mathrm{~Hz}$. The difference is approximately $3.35 \%$. Therefore, the results of this model have a certain stability.

As shown in Figure 3, with the increase of pipe length, the influence of annulus constraints on the natural frequency of the string gradually increases and the difference between the natural frequencies under the two boundary conditions increases. When the string length is less than $300 \mathrm{~m}$, the influence of the annulus constraint on the natural frequency of the string is not significant. When the length of the string

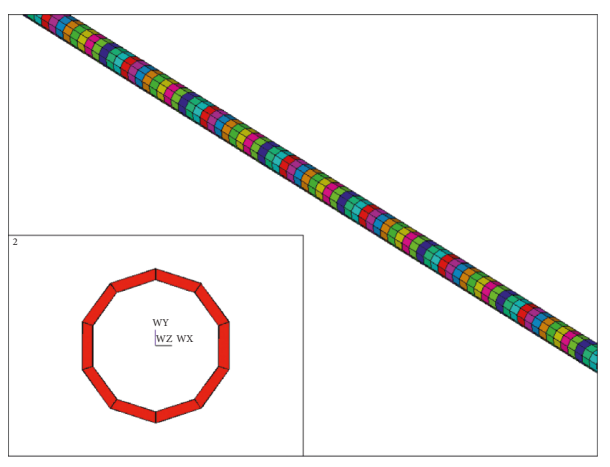

(a)

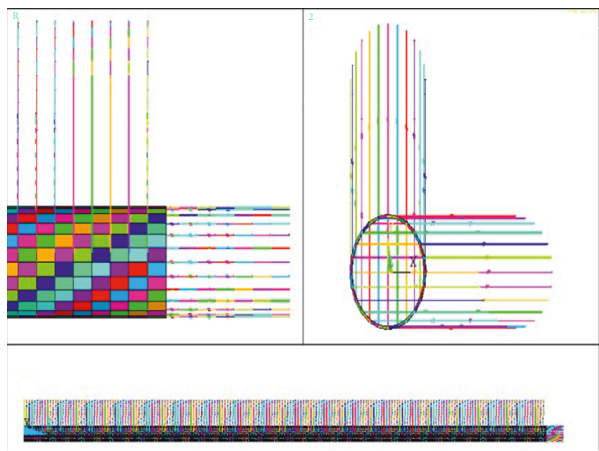

(b)

Figure 2: Three-dimensional finite element model of the gas storage well string. (a) Finite element model of injection and production string. (b) Mesh result of the finite element model.

is approximately $200 \mathrm{~m}$, the natural frequency value without considering the annulus constraint is $0.865 \times 10^{-1} \mathrm{~Hz}$ and the natural frequency value considering the annulus constraint is $0.874 \times 10^{-1} \mathrm{~Hz}$, while the numerical value is $0.901 \times 10^{-1} \mathrm{~Hz}$. The difference is approximately $1.06 \%$. When the length of the string exceeds $400 \mathrm{~m}$, the natural frequency of the string considering the annulus constraint is significantly greater than it is without considering the annulus constraint. When the length of the string is approximately $600 \mathrm{~m}$, the natural frequency value without considering the annulus constraint is $0.129 \times 10^{-1} \mathrm{~Hz}$ and the natural frequency value considering the annulus constraint is $0.161 \times 10^{-1} \mathrm{~Hz}$, while the numerical value is $0.165 \times 10^{-1} \mathrm{~Hz}$. The difference is approximately $24.01 \%$. When the length of the string is approximately $800 \mathrm{~m}$, the natural frequency value without considering the annulus constraint is $0.118 \times 10^{-1} \mathrm{~Hz}$ and the natural frequency value considering the annulus constraint is $0.149 \times 10^{-1} \mathrm{~Hz}$, while the numerical value is $0.153 \times 10^{-1} \mathrm{~Hz}$. The difference is approximately $26.48 \%$. The results show that if the string is long enough, the constraint of the tube-casing annulus on the injection and production string must be taken into account when designing the safety string.

Figure 4 is an analysis chart of the influence of the damping of the gas storage well string system on the string vibration. It can be seen from the curve of the result calculated by the model in this paper that when the frequency of the excitation is close to a fundamental frequency of the string, the amplitude of the string will greatly increase and 
TABLE 1: Parameters of gas injection string of gas storage.

\begin{tabular}{lccccc}
\hline String & Density & Modulus of elasticity & Poisson's ratio & Coefficient of expansion & Thermal conductivity \\
\hline$\varnothing 114.3 \times 14.22 \mathrm{~mm}$ & $7800 \mathrm{~kg} \cdot \mathrm{m}^{-3}$ & $2.1 \times 10^{5} \mathrm{MPa}$ & 0.30 & $12.2 \times 10^{-6 \circ} \mathrm{C}$ & $45.0 \mathrm{~W}(\mathrm{~m} \cdot \mathrm{K})^{-1}$ \\
\hline
\end{tabular}

TABLE 2: Design parameters of gas storage.

\begin{tabular}{|c|c|c|c|c|c|c|c|c|}
\hline $\begin{array}{l}\text { Operating } \\
\text { pressure }\end{array}$ & Depth & $\begin{array}{c}\text { Geothermal } \\
\text { gradient }\end{array}$ & Porosity & Permeability & $\begin{array}{l}\text { Design value of } \\
\text { storage capacity }\end{array}$ & $\begin{array}{c}\text { Working gas } \\
\text { volume }\end{array}$ & $\begin{array}{l}\text { Reservoir } \\
\text { thickness }\end{array}$ & $\begin{array}{c}\text { Gas } \\
\text { injection } \\
\text { time }\end{array}$ \\
\hline $10 \sim 40 \mathrm{MPa}$ & $3174 \mathrm{~m}$ & $3.1^{\circ} \mathrm{C} / 100 \mathrm{~m}$ & $16.2 \sim 22.3 \%$ & $2.46 \times 10^{-3} \mu \mathrm{m}^{2}$ & $10.4 \times 10^{8} \mathrm{~m}^{3}$ & $5 \sim 8 \times 10^{8} \mathrm{~m}^{3}$ & $10 \mathrm{~m}$ & 90 days \\
\hline
\end{tabular}

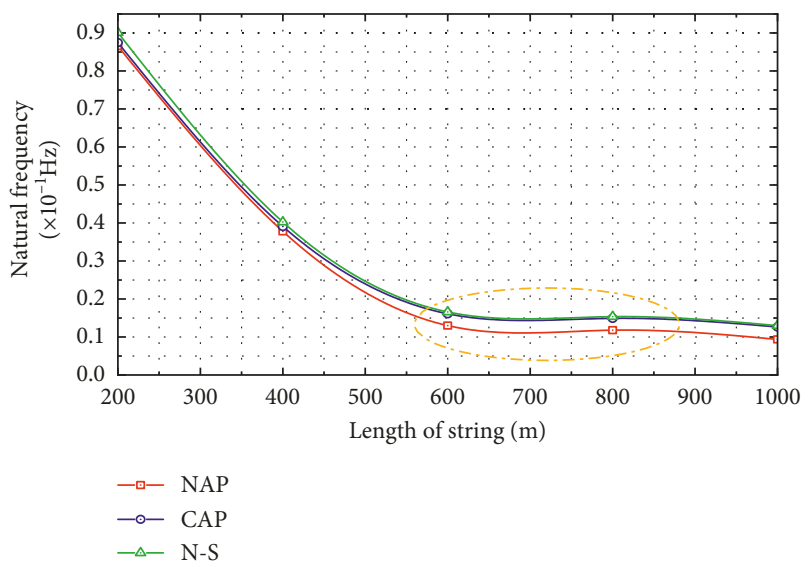

FIgURE 3: Curve of relationship between length and natural frequency for two conditions.

the "saddle like" distribution is produced, which is obviously larger than the amplitude produced by other frequencies. Therefore, it can be confirmed that the string is resonant under this condition and the corresponding excitation frequency is the excitation frequency domain that induces resonance of the string. When the damping is 0.1 , the excitation frequencies inducing the "saddle like" distribution characteristics of the string are $0.0301 \mathrm{~Hz}, 0.0546 \mathrm{~Hz}$, and $0.0902 \mathrm{~Hz}$, respectively. The corresponding amplitude is $0.357 \mathrm{~m}, 0.0185 \mathrm{~m}$, and $0.122 \mathrm{~m}$, and the difference between the value calculated by the model in this paper and the output results of the software is $9.23 \%, 4.86 \%$, and $4.91 \%$, respectively, which validate the calculation results of the amplitude characteristic.

At the same time, from Figures 4(a)-4(c), it is known that with an increase in damping, the amplitude of the string will change correspondingly under the same excitation frequency. When the damping of the string system is 0.10 , $0.15,0.20$, and 0.25 , respectively, the "saddle-like" characteristic amplitude $(f=0.0301 \mathrm{~Hz})$ of the string is $0.357 \mathrm{~m}$, $0.315 \mathrm{~m}, 0.225 \mathrm{~m}$, and $0.206 \mathrm{~m}$, respectively, indicating that the greater the damping, the smaller the amplitude of the string when the string resonates. Therefore, increasing the damping of the string system can effectively reduce the effect of resonance.

Through analysis of the natural frequency characteristics and harmonic response analysis of the injection and production string, the excitation effect on the injection and production string caused by injection and production pressure fluctuation is studied and the induced effect of the excitation frequency on the string vibration is obtained. Considering the multiperiod forced injection and forced production of the gas storage, the instantaneity and variability of the pressure fluctuation will have a great influence on induced string vibration, so the transient dynamic response of the gas storage string in a gas reservoir should be further analyzed.

3.4. Transient Dynamic Response Analysis of Strings. Due to the instability of high-speed gas flow, the injection and production pressure in the gas storage well during stable production process has a certain range of fluctuation; that is, there is a certain fluctuation range of the real load. Therefore, in order to get closer to real working conditions, intermittent random fluctuation pressure is added when analyzing the transient dynamic response of injection and the production string. Figure 5 shows the value of the internal pressure as applied to the three-dimensional string model. The static pressure $P_{0}$ is $30 \mathrm{MPa}$, the fluctuation pressure difference is $10 \mathrm{MPa}$, and the running time is $30 \mathrm{~s}$.

The transient dynamic response of the string at different positions away from the packer is shown in Figures 6(a)6(c). From Figure 6, it can be seen that the instability of high-speed natural gas will cause fluctuation of internal pressure during the steady injection and production process and then, the fluctuation will cause periodic disturbance of the axial displacement of the string; the closer the position of the string to the packer, the smaller the amplitude, speed, and acceleration of the string. The farther away from the packer the position of the string is, the greater the amplitude, speed, and acceleration of the string. The reason is that as the distance from the packer increases, the flexibility of the string will increase and the elastic deformation and the space of movement will also increase. It can be seen that, compared with the shutdown well process and the initial injection and production stage, the vibration degree of the string in the stable injection and production process is smaller and the main vibration is the longitudinal vibration of the string.

To study the influence of pressure fluctuation on the frequency domain of string vibration, the numerical results of different positions away from packers (A-F-P) at $100 \mathrm{~m}$, $200 \mathrm{~m}, 300 \mathrm{~m}$, and $400 \mathrm{~m}$ are analyzed, as shown in Figure 7. 


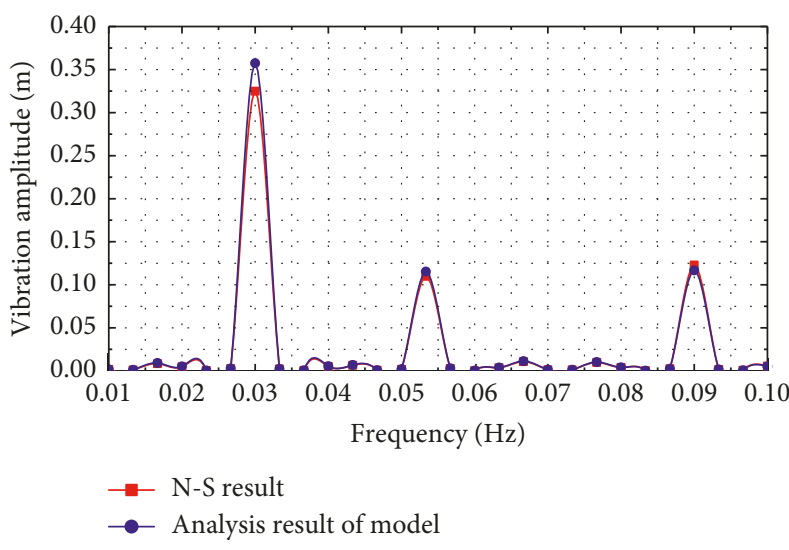

(a)

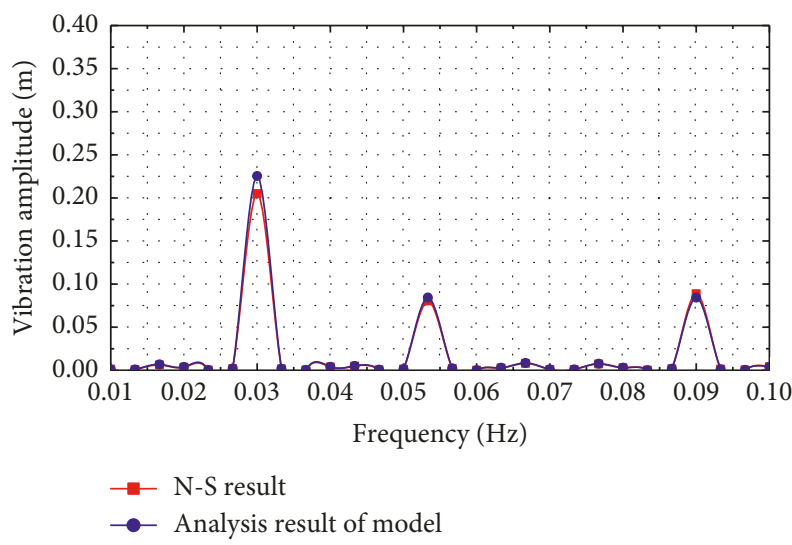

(c)

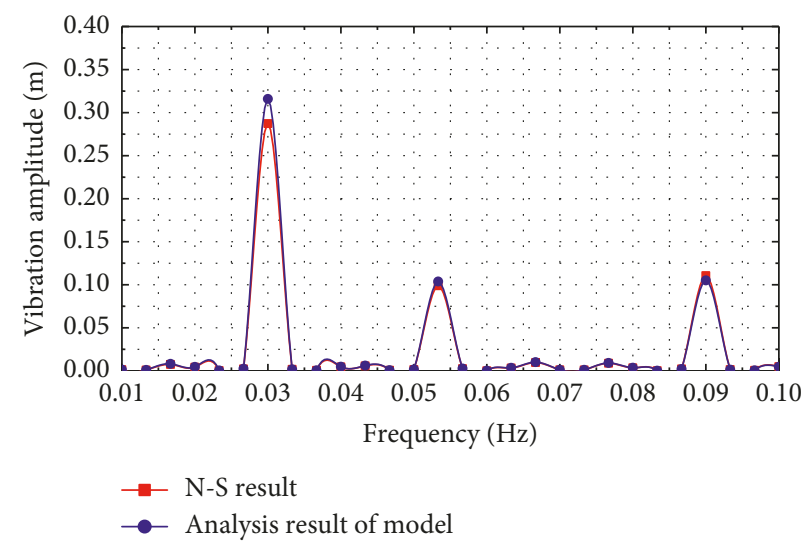

(b)

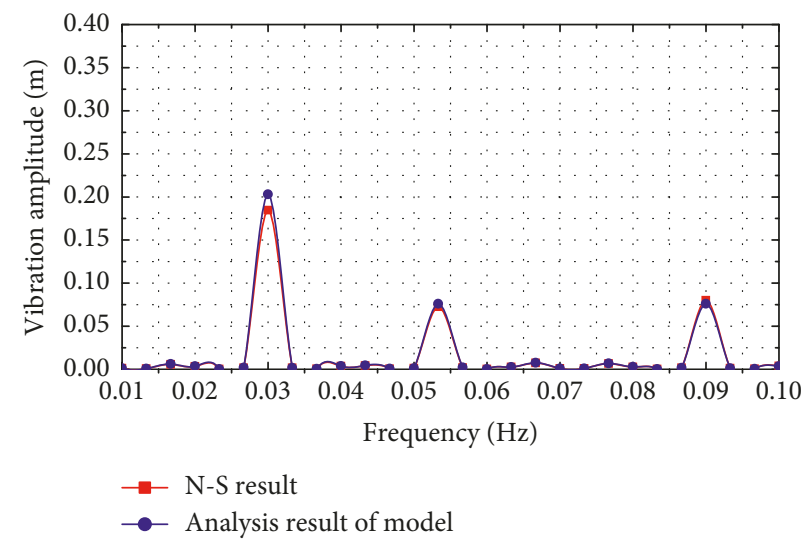

(d)

Figure 4: Curves of amplitude-frequency and phase-frequency characteristics under different damping values: (a) 0.10, (b) 0.15, (c) 0.20, and (d) 0.25 .

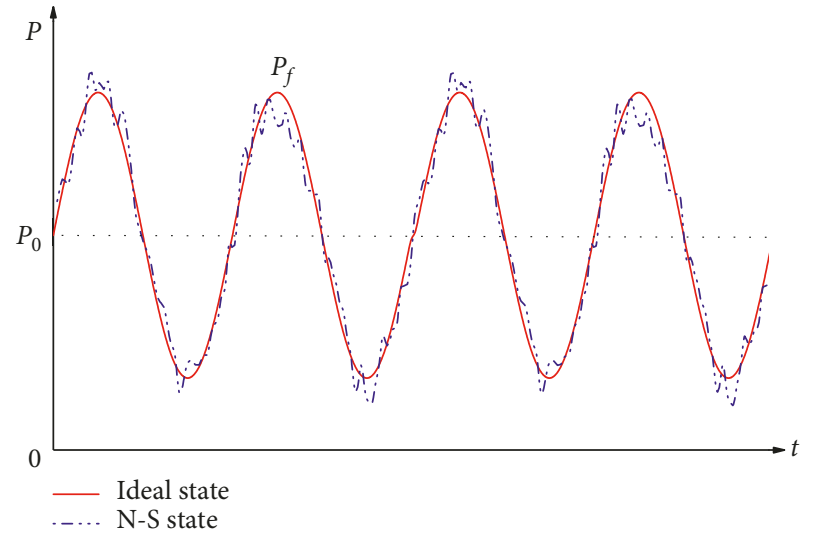

Figure 5: Internal pressure values imposed by the model.

Here, we can see that the trend of frequency-domain distribution of vibration at different positions has similar regularity. In the low-frequency pressure excitation area, the time-domain displacement response amplitude of the string structure is larger, indicating that the structural frequency decreases with the elongation of the string structure. When the excitation frequency is close to the low-order natural frequency of the system, the string will vibrate noticeably and the fluctuation range of vibration amplitude is approximately $0 \sim 3.3 \mathrm{~mm}$. It can be seen that low-frequency pressure fluctuation is an important excitation source for vibration of strings in the production process.

At the same time, from Figure 7, we can see that, in the frequency range of $0 \mathrm{~Hz}$ to $50 \mathrm{~Hz}$, the closer the position (from $400 \mathrm{~m}$ to $100 \mathrm{~m} \mathrm{D}-\mathrm{T}-\mathrm{P}$ ) is to the packer, the smaller the vibration amplitude. The maximum amplitude of the position $L=400 \mathrm{~m}$ is approximately $3.18 \mathrm{~mm}$, the maximum amplitude of the position $L=200 \mathrm{~m}$ is approximately $1.83 \mathrm{~mm}$, and the maximum amplitude of the position $L=100 \mathrm{~m}$ is approximately $1.71 \mathrm{~mm}$. The vibration amplitude of the string near the packer does not increase with the decrease of the frequency of the string, of which the main reason is that the bottom hole packer has a solid constraint on the string. Therefore, for security, a packer device can be properly used to reduce the fatigue effect caused by an alternating load.

\section{Experimental Study on Nonlinear Vibration of Tubing String}

4.1. Experimental Design. According to the working condition data, an experimental device is set up. The tubing used in the experiment is made of stainless steel pipe, the length is approximately $8.5 \mathrm{~m}$, the design pressure is $10 \mathrm{MPa}$, and the 


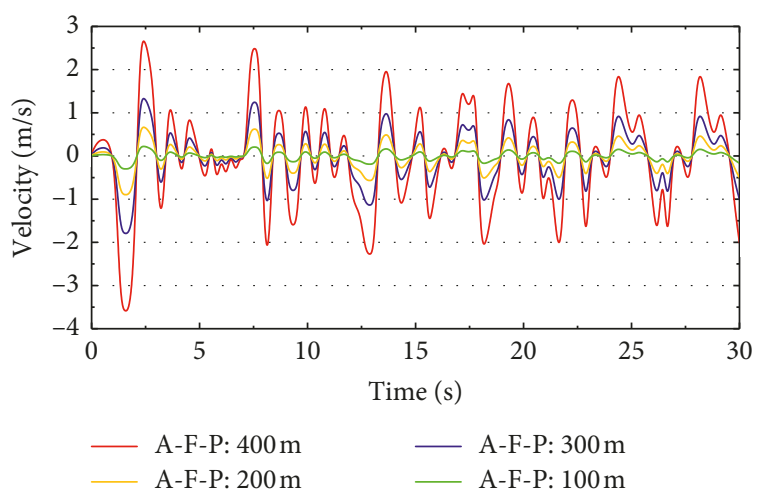

(a)

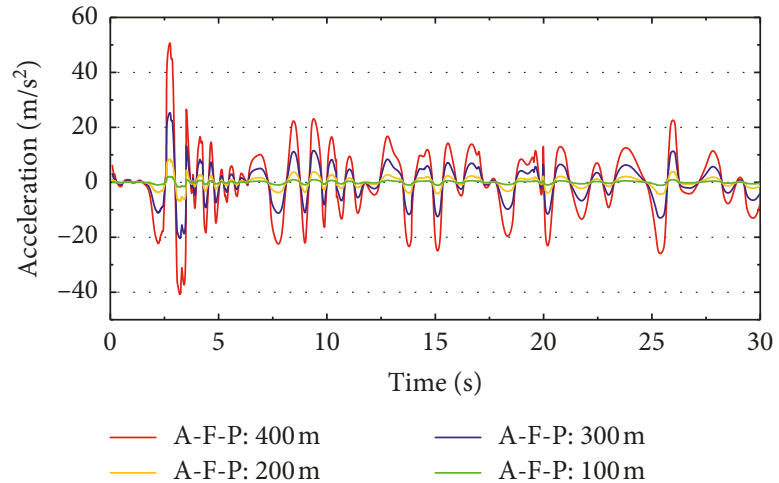

(b)

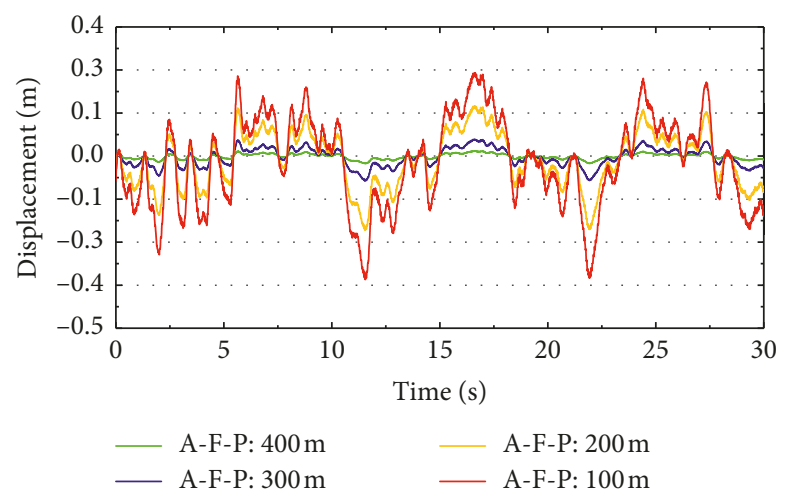

(c)

Figure 6: Curve of pipeline dynamic response analysis at different positions of the packer. (a) Axial velocity. (b) Axial acceleration. (c) Axial displacement.

maximum pressure is $16 \mathrm{MPa}$. As shown in Figure 8 , the experimental device is set up according to the injection mode of "vertical well section-inclined well section-horizontal section \#1-horizontal section \#2-gas storage." At the same time, 8 measuring points are set up between the starting point and the end point, and the measuring points are, respectively, located at the gas injection inlet, inclined well section, and horizontal section, etc. In addition, the position of the measuring points can be changed according to the needs of the experiment. The gas injected in the experiment is compressed air, and the physical properties of the compressed air are similar to those of natural gas, which can meet the needs of both experimental results and device safety. In the process of design, a similarity analysis between the experimental system and the actual gas storage well is carried out (shown in Table 3). The similarity results are good, so the experimental device can be used in monitoring and simulation function of nonlinear vibration of gas storage string in a depleted oil and gas reservoir during the gas injection process.

The experimental system includes hardware units and a data acquisition unit. The hardware units are composed of an air compressor, a booster pump, an air storage tank, an oil pipeline, a sensor, and so on. The layout of the experimental hardware units is shown in Figure 9. In the experiment, the flow rate can be provided by the air compressor. The pressure gas is provided by a booster pump and the gas storage tank. The gas inflow pressure is controlled by the gas mass flow controller. The differential pressure meter is used to measure the pressure difference of each experimental tube.

The pressure sensors (PM), displacement sensors (DM), speed sensors (VM), and other data elements are added to the measuring point position in order to measure and collect the near-wall pressure, the displacement, and the velocity value of each measuring point. The distribution of the data elements at the measuring points of the nonlinear vibration test of the gas storage is shown in Figure 10.

The real-time data acquisition system of the experimental device also includes a PCI-1711 conventional data acquisition card and a PCI-4472 dynamic data acquisition card, both of which have unique circuit designs and perfect data acquisition and control functions. Because the amplitude and frequency of the experimental signal change very fast, it is imperative that the data acquisition card be used for high-speed data acquisition. The data acquisition cards used in this experimental device can collect high-speed data, which ultimately can ensure the real-time data acquisition and experimental accuracy.

4.2. Experimental Process. The experimental process is as follows: the gas source used in the experiment is compressed air. The gas is pressurized by using a compressor, dried by using a cold dryer and filter, and then pumped into a pipe 


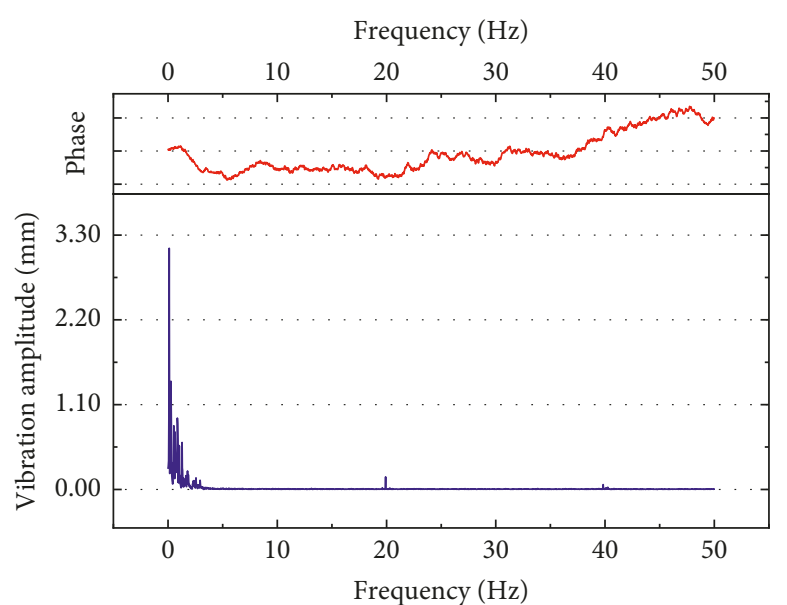

(a)

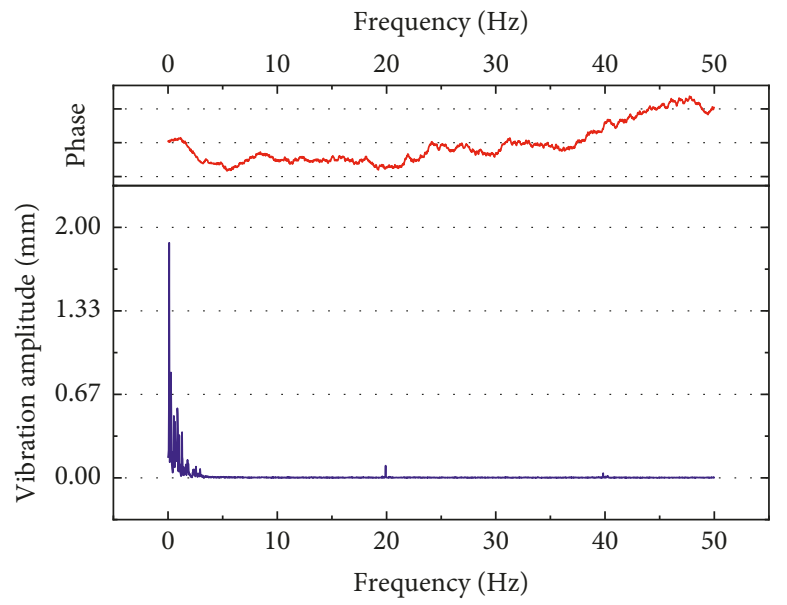

(c)

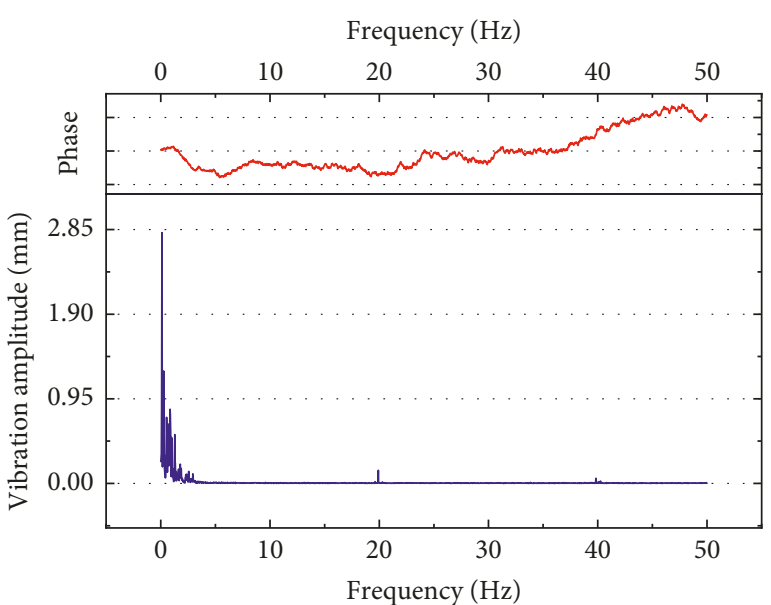

(b)

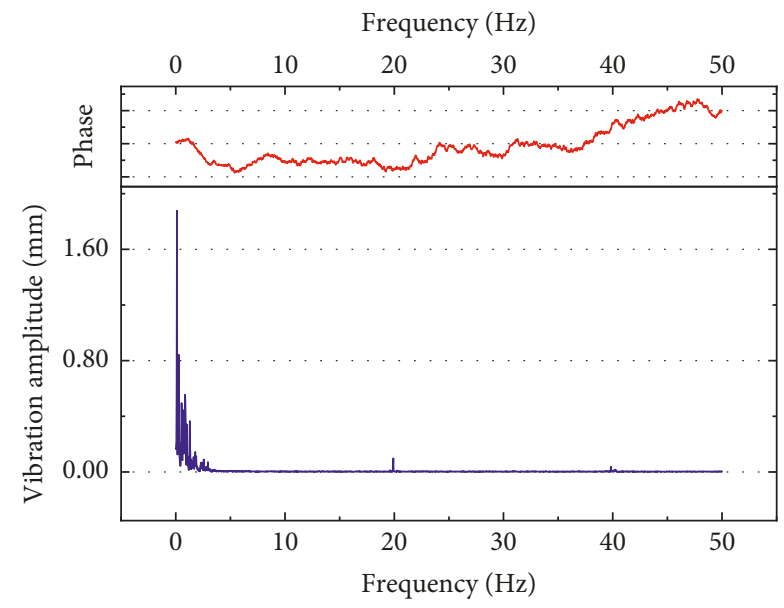

(d)

Figure 7: Analysis results of simulated data change. (a) A-F-P: 400 m. (b) A-F-P: 300 m. (c) A-F-P: 200 m. (d) A-F-P: 100 m.

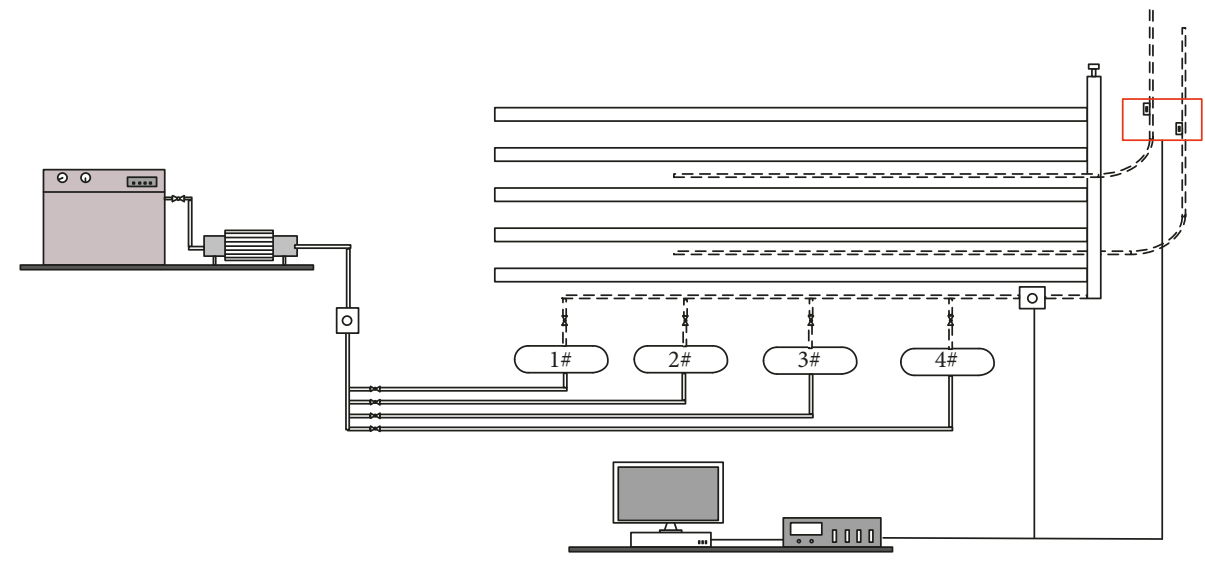

Figure 8: Experimental setup.

section by using a high-pressure compressor. A flow control ball valve is used to measure steady gas outflow. At the same time, openings of the gas valves are used to simulate the bottom hole and wellhead. The pressure gas flows from "vertical well section-inclined well section-horizontal section \#1-horizontal section \#2" to the high-pressure storage tank which is used to simulate the gas storage tank. The pressure gas continuously outflows, and the feedback data of the sensors are recorded. Finally, the gas cylinder is closed. When the release process of gas pressure in the tubing is finished, the experiment is finished, that is to say, simulation experiment of the nonlinear vibration of string of the gas 
TABLe 3: Comparison of experimental tubings and real tubings.

\begin{tabular}{lcccccc}
\hline \multirow{2}{*}{ Type } & \multicolumn{3}{c}{ Real tubings $(\mathrm{mm})$} & \multicolumn{3}{c}{ Experimental tubings (mm) } \\
& External diameter & Internal diameter & Wall thickness & External diameter & Internal diameter & Wall thickness \\
\hline Parameter & 114.3 & 100.53 & 6.885 & 3.81 & 3.351 & 0.23 \\
\hline
\end{tabular}

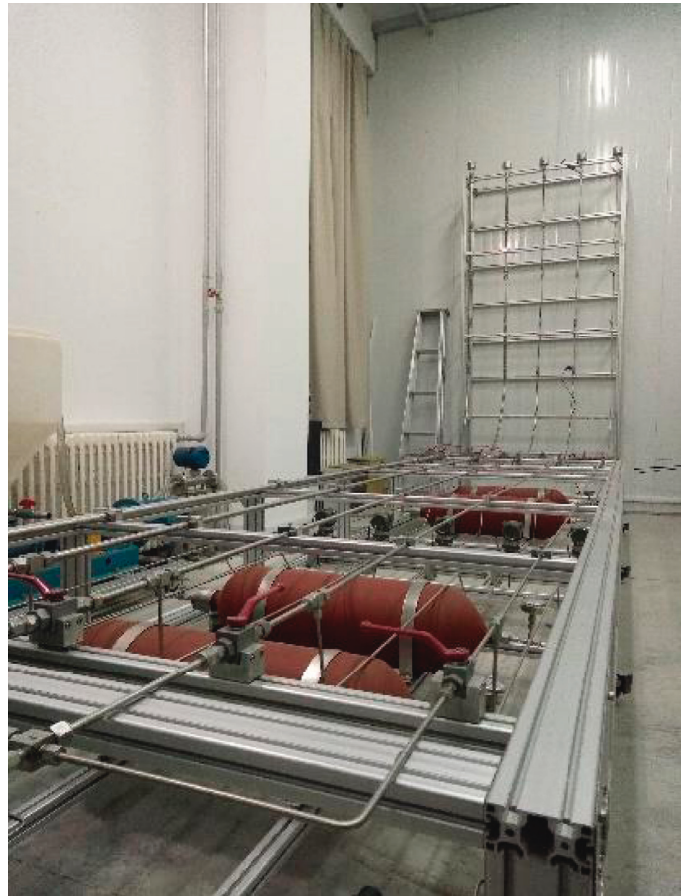

(a)

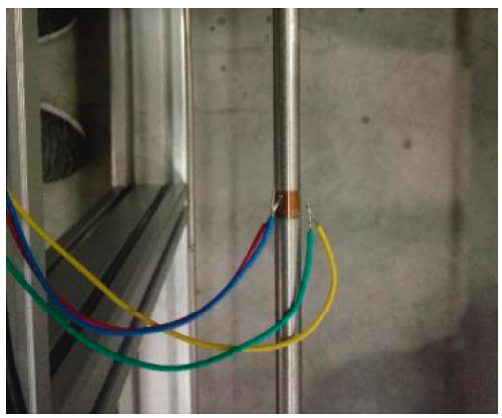

(b)

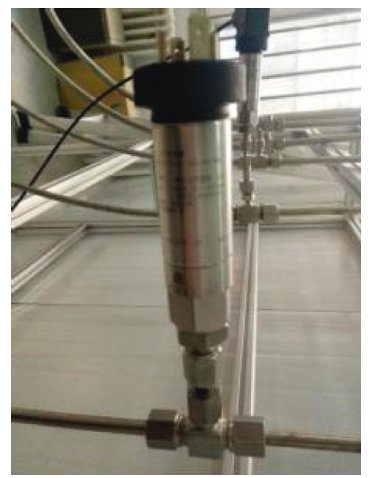

(c)

FIGURE 9: Hardware experimental device for simulation of injection and production in UGS.
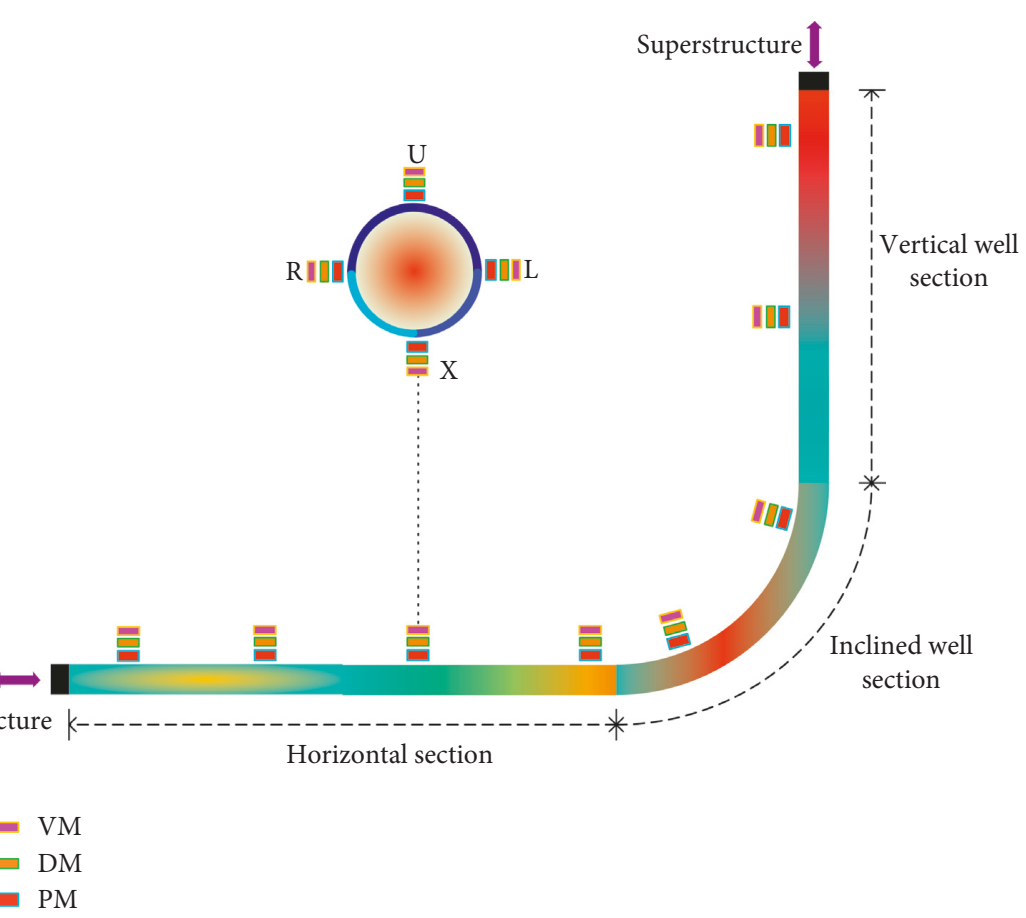

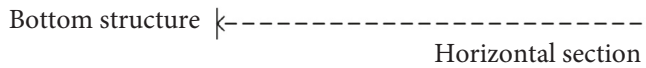

$$
\begin{array}{r}
=\mathrm{VM} \\
\square \mathrm{DM} \\
-\mathrm{PM}
\end{array}
$$

FIGURE 10: Gas storage nonlinear vibration measurement point data element distribution. 
storage in depleted oil and gas reservoir in the gas injection process is completed.

4.3. Experimental Results and Discussion. Referring to the simplified condition proposed by Tijsseling [16], the effect of tubing gravity on the experimental results is ignored, and it is determined that the moment of inertia of the whole pipeline is zero. The experimental simulation conditions are as follows: gas injection flow is $30 \times 10^{4} \mathrm{~m}^{3} \cdot \mathrm{d}^{-1}$, the pressure drop along the way is $8 \mathrm{MPa}$, the overall angle change rate is $9^{\circ} / 30 \mathrm{~m}$, the oil pressure is $33 \mathrm{MPa}$, and the wellhead temperature is $25^{\circ} \mathrm{C}$. The experimental results of the distribution of near-wall pressure of the tubing are compared with the field results, as shown in Table 4.

The experimental results of distribution of the near-wall pressure of tubing (vertical well section-inclined well section-horizontal section \#1-horizontal section \#2) are compared with the field results, as shown in Table 4 . The results show that the relative errors of the experimental results and the field results of these sections are $6.27 \%, 7.58 \%, 4.82 \%$, and $5.31 \%$, respectively, which meet the needs of practical engineering. The maximum variance of the experimental results is 3.85 , and the maximum variance of the field results is 3.99 , which means that the fluctuation of the experimental results is smaller than that of the field results. It can be seen that the above experimental design is stable and practical. To study the vibration characteristics of the well string of gas storage in depleted oil and gas reservoir in the gas injection process, the change rules of the string pressure, the wall velocity, and the amplitude in the gas injection process are further studied.

4.3.1. Analysis of String Near-Wall Pressure Change in the Gas Injection Process. The string near-wall pressure of three sets of measuring points $\mathrm{A}, \mathrm{B}$, and $\mathrm{C}$ (vertical well sectioninclined well section-horizontal section) varies with time during the gas injection process, as shown in Figure 11. It can be seen from Figures 11(a)-11(c) that the string nearwall pressure rises rapidly, and then, the pressure fluctuates cyclically in a certain range. As shown in Figure 11(a), the gas pressure in the vertical well section is periodically oscillatory and has a wide fluctuation and the gas pressure remains stable after $t=0.136 \mathrm{~s}$. As shown in Figure 11(b), the gas pressure in the inclined well section is multistage concussive after $t=0.164 \mathrm{~s}$ and the variation range increases. It shows that the near-wall pressure of the vertical well section and the inclined well section changes greatly, of which the effect on the string is obvious. As shown in Figure 11(c), the gas pressure in the horizontal section remains stable during the transmission process, showing a cyclical alternation; then, the amplitude of the change gradually decreases, and the alternating cycle gradually becomes longer.

4.3.2. Analysis of the Tubing Wall Velocity Change in the Gas Injection Process. The tubing wall velocity of three sets of measuring points A, B, and C (vertical well section-inclined well section-horizontal section) varies with time in gas injection process, as shown in Figure 12. It can be seen from Figures 12(a)-12(c) that the vibration velocity of the tubing as predicted by the numerical method is basically the same as the experimental value.

It is known from Figures 12(a)-12(c) that, in the continuous injection process, the velocity of the vertical well section, inclined well section, horizontal section \#1, and horizontal section \# 2 changes periodically. With an increase in the injection flow, the velocity of each section varies predictably and the trend of the speed change is fast first and then slow. At the same time, Figure 12(a) shows that after opening the flow control valve, the injection gas quickly enters the experimental device in the vertical well section, and that the wall velocity of the vertical well section rises rapidly and then gradually fluctuates periodically in a certain range with a high frequency of fluctuation. Figure 12(b) shows that after the injection and production gas enters the inclined well section, the fluctuation peak of the wall velocity decreases with the influence of flow resistance and wall friction. However, after $t=0.02 \mathrm{~s}$, the wall velocity cyclically alternates and the alternating cycle gradually becomes shorter. Figure 12(c) shows that the wall velocity decreases slowly with an increase in the lift and the alternating cycle becomes larger and the wall velocity gradually tends to be stable.

4.3.3. Analysis of the Change of Displacement Amplitude of Tubing Wall in the Gas Injection Process. The displacement amplitude of the tubing wall of three sets of measuring points $A, B$, and $C$ (vertical well section-inclined well section-horizontal section) varies with time in the gas injection process, as shown in Figure 13. The variation trends of nonlinear vibration amplitude of the vertical well section, the inclined well section, the horizontal section \#1, and the horizontal section $\# 2$ are similar to those of the wall velocity. With an increase in injection flow, the change of amplitude in each section shows a periodic change.

At the same time, Figure 13(a) shows that the displacement amplitude of the tubing wall in the vertical well section ranges from 1.5 to $4 \mathrm{~mm}$ and that the amplitude gradually stabilizes in a certain range after $t=0.056 \mathrm{~s}$. As shown in Figures 13(b) and 13(c), the wall velocity decreases but the displacement amplitude increases and the alternating cycle is small, which indicates that the vortex section is formed in the inclined well section and its effect on the tubing wall excitation is obvious. From the inclined well section to the horizontal section, the variation of the displacement amplitude gradually decreases and the alternating period becomes longer, and it is the author's opinion that the reason for the occurrence of this phenomenon is related to the compressibility of gas and the wall friction resistance. During the experiment, both the vertical well section and the inclined well section have a certain degree of shock. Combined with analysis of the previous results, it shows that the first section of gas injection and the inclined well section are high-incidence 
TABLE 4: Near-wall pressure test results and field results.

\begin{tabular}{|c|c|c|c|c|c|c|c|c|}
\hline \multirow[t]{2}{*}{ Number } & \multicolumn{2}{|c|}{$\begin{array}{l}\text { Vertical well section } \\
\qquad(\mathrm{MPa})\end{array}$} & \multicolumn{2}{|c|}{$\begin{array}{l}\text { Inclined well section } \\
(\mathrm{MPa})\end{array}$} & \multicolumn{2}{|c|}{$\begin{array}{l}\text { Horizontal section } \\
\quad \# 1(\mathrm{MPa})\end{array}$} & \multicolumn{2}{|c|}{$\begin{array}{l}\text { Horizontal section } \\
\quad \# 2(\mathrm{MPa})\end{array}$} \\
\hline & Test & Field & Test & Field & Test & Field & Test & Field \\
\hline 1 & 21.23 & 20.20 & 20.97 & 19.68 & 18.92 & 18.17 & 17.98 & 17.17 \\
\hline 2 & 21.19 & 19.50 & 20.92 & 19.01 & 21.48 & 20.56 & 20.44 & 19.47 \\
\hline 3 & 20.56 & 18.96 & 20.17 & 18.46 & 23.42 & 22.30 & 22.42 & 21.25 \\
\hline 4 & 18.82 & 17.72 & 19.68 & 19.12 & 25.71 & 24.42 & 24.71 & 23.32 \\
\hline 5 & 11.17 & 10.19 & 25.051 & 24.40 & 25.06 & 23.94 & 23.97 & 22.76 \\
\hline 6 & 10.53 & 9.42 & 24.54 & 21.79 & 23.42 & 22.34 & 22.42 & 21.28 \\
\hline 7 & 16.33 & 16.62 & 20.87 & 19.01 & 23.05 & 21.99 & 22.05 & 20.93 \\
\hline 8 & 17.02 & 16.14 & 16.81 & 15.76 & 22.32 & 21.29 & 21.25 & 20.17 \\
\hline Average value & 17.17 & 16.09 & 21.12 & 19.63 & 22.92 & 21.85 & 21.95 & 20.80 \\
\hline Relative error (\%) & \multicolumn{2}{|c|}{6.27} & \multicolumn{2}{|c|}{7.58} & \multicolumn{2}{|c|}{4.82} & \multicolumn{2}{|c|}{5.31} \\
\hline Variance & 3.99 & 3.85 & 2.47 & 2.37 & 1.97 & 1.83 & 1.96 & 1.81 \\
\hline
\end{tabular}

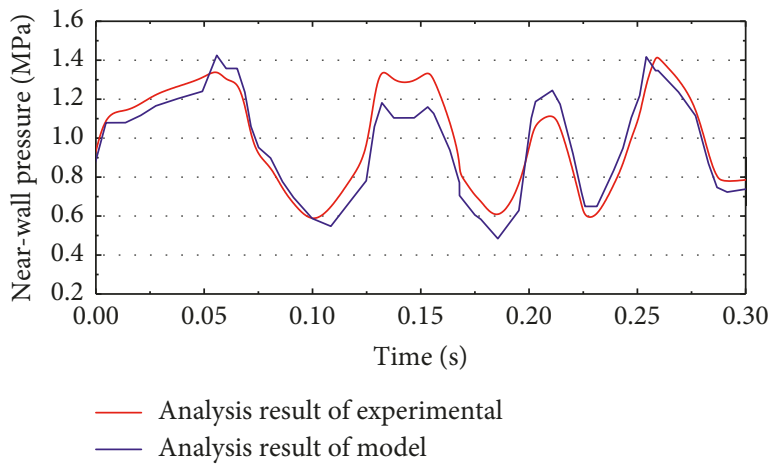

(a)

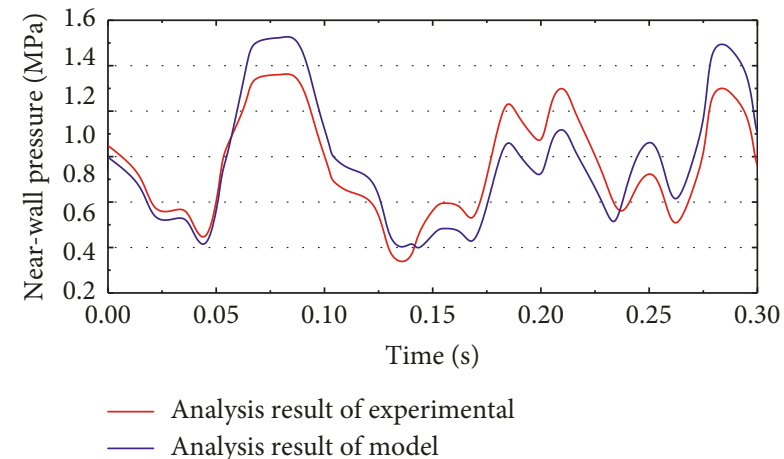

(b)

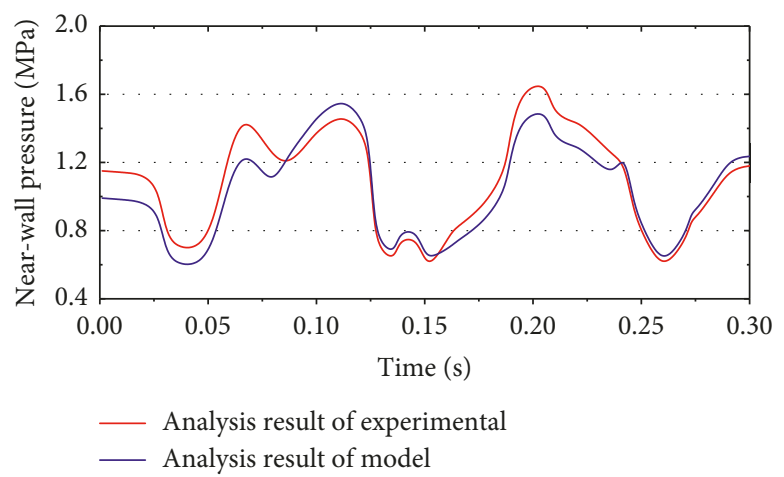

(c)

FIGURE 11: Variation of pressure in the wall of the pipe with time during gas injection. (a) Vertical well section. (b) Inclined well section. (c) Horizontal section.

areas of the nonlinear vibration of the gas storage well string in a depleted oil and gas reservoir. Corresponding safety measures should be made in the design and operation of safety production.

\section{Conclusion}

In this paper, a method of nonlinear vibration analysis of tubing strings in underground gas storage using string multiscale wavelet transform has been developed. The vibration characteristics of strings in the steady gas injection process have been analyzed by means of numerical simulation. The nonlinear vibration experiment of strings in the gas injection process has been studied. As an application, the dynamic characteristics and frequency-domain characteristics of the gas storage well string in the wellbore were studied. The results show that the longer the tubing string, the greater the influence of the annulus constraints on the frequency of the tubing string. This behavior of the string plays a major role when a sudden pressure change in the strings causes vibration. Significant alteration of the dynamics owes to a low-frequency pressure fluctuation force on the tubing string. During the injection process, the nearwall pressure and displacement amplitude of the tubing 


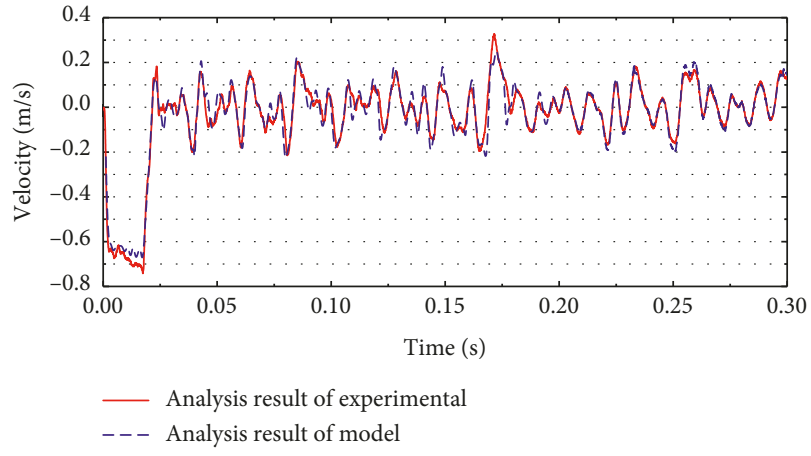

(a)

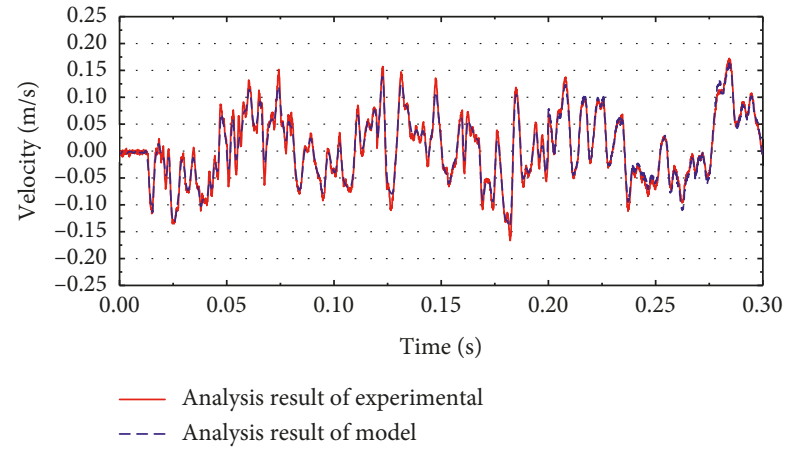

(b)

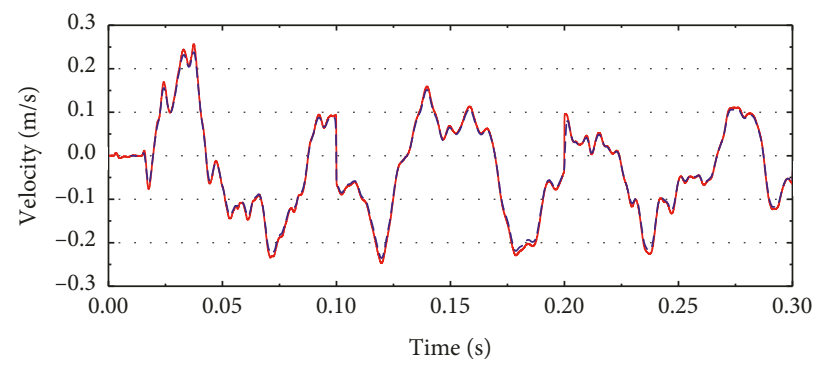

- Analysis result of experimental

- - Analysis result of model

(c)

Figure 12: Variation of tubing wall velocity with time in gas injection. (a) Vertical well section. (b) Inclined well section. (c) Horizontal section.

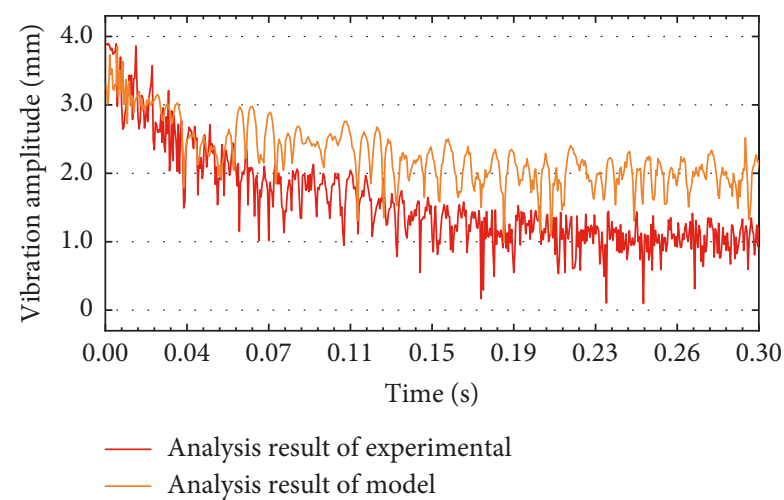

(a)

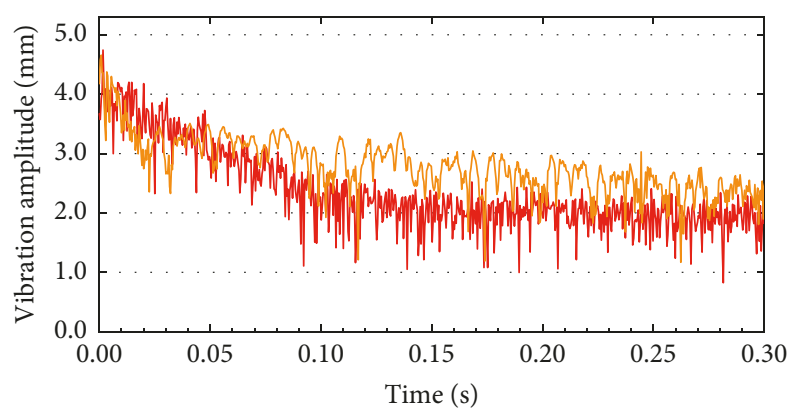

_ Analysis result of experimental

_ Analysis result of model

(b)

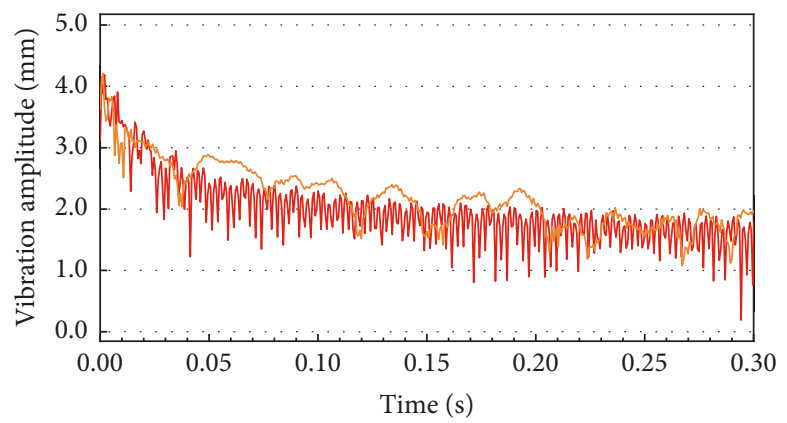

- Analysis result of experimental Analysis result of model

(c)

Figure 13: Variation of displacement amplitude of tubing wall with time during gas injection. (a) Vertical well section. (b) Inclined well section. (c) Horizontal section. 
string are similar to the wall velocity. With an increase in injection flow rate, the amplitude of each tubing string changes significantly and periodically. We also find that the near-injection port section and the inclined section of strings are high-incidence areas of nonlinear vibration of strings in underground gas storage. In conclusion, the method of nonlinear vibration analysis of tubing strings in underground gas storage using multiscale wavelet transform can provide a good prediction of pressure with acceptable precision for studying the vibration characteristics of tubing string. Safety measures should be taken for production design and operation.

\section{Abbreviations}

$h_{i}$ : Length of the $i$-th string

$r$ : Inside diameter

$R: \quad$ Outside diameter

$f_{0}$ : Pressure inside the tube

$V$ : Volume of liquid

$f_{1}$ : Annulus pressure

$\Delta v$ : Volume change

$\Delta F$ : Spring effect force

$k$ : $\quad$ Stiffness of spring

$A_{i}$ : Cross-sectional area

$E_{i}$ : $\quad$ Elastic modulus

$\rho_{i}:$ Density

$v_{i}:$ Poisson's ratio

$\delta_{i}$ : Damping coefficient

$u_{i}$ : Longitudinal displacement

$f_{i}$ : Sum of the force on the unit length of the upper and lower ends of the $i$-th string

$\Delta f:$ Annulus pressure value

$c_{i}$ : Longitudinal shear complex stiffness

$w_{0}$ : Center frequency of wavelet

$P_{j, 0}$ : Initial reservoir pressure

$P: \quad$ Pressure function

$G_{\mathrm{g} i}$ : Mass flow

$\chi$ : Pressure transmitting coefficient

$t: \quad$ Time

$r_{\mathrm{c}}:$ Radius

$q_{i}: \quad$ Formation pressure

$w_{i}$ : Frequency

$h$ : Length.

\section{Data Availability}

The data that support the findings of this study are available from the corresponding author on reasonable request, but restrictions apply to the availability of these data, which were used under license for the current study, and so they are not publicly available. Data are, however, available from the authors upon reasonable request and with permission of the corresponding author.

\section{Conflicts of Interest}

The authors declare that they have no conflicts of interest.

\section{Acknowledgments}

This study was financially supported by the National Natural Science Foundation of China (Grant no. 51804330), China Postdoctoral Science Foundation (Grant no. 2017M612375), Fundamental Research Funds for the Central Universities of China (Grant no. 18CX02154A), and National Science and Technology Major Project of China (Grant no. 2016ZX05017-003).

\section{References}

[1] W. Huan, J. Tian, and J. Li, "Current status and development trend of natural gas underground gas storage in China," International Petroleum Economy, vol. 23, no. 6, pp. 57-62, 2015.

[2] G. Yuan, W. Xia, G. Jin et al., "Status quo of underground storage at home and abroad and development trend of engineering technology," Petroleum Drilling Techniques, vol. 45, no. 4, pp. 8-14, 2017.

[3] M. J. Economides and X. Wang, "A modern approach to optimizing underground natural gas storage," in Proceedings of the SPE Annual Technical Conference and Exhibition, p. 166080, New Orleans, LA, USA, September 2013.

[4] A. Kyllingstand, "Buckling of tubular strings in curved wells," Journal of Petroleum Science and Engineering, vol. 12, no. 3, pp. 209-218, 1995.

[5] Y. Yan, Safety Analysis of the Construction of the Gas String in the Deep Cave Salt Storage Gas Reservoir, China University of Petroleum, Beijing, China, 2016.

[6] J. Ding, Z. Lian, and R. Ding, "Static and dynamic safety evaluation and software development of injection pipe string in gas storage," Petroleum Drilling Technology, vol. 40, no. 2, pp. 215-221, 2018.

[7] M. Liu, Y. Yan, and W. Xie, "Experimental study of fluid nearwall pressure in gas well string based on self-similar model," Journal of China University of Petroleum (Natural Science Edition), vol. 41, no. 2, pp. 147-155, 2017.

[8] M. Stefan and J. C. Cunha, "An analysis of helical buckling of tubulars subjected to axial and torsional loading in inclined wellbores," Journal of Energy Resources Technology, vol. 4, no. 2, pp. 170-180, 1995.

[9] M.-J. Yang, L. I. Hai-tao, and R. Jiang, "Study on vibration damage of completion strings in high-production gas wells in yula county," Journal of Southwest Petroleum University (Natural Science), vol. 38, no. 1, pp. 158-163, 2016.

[10] Y. Dou and L. I. U. J. Leiqi, "Analysis of vibration safety of completion strings under switching well conditions," Oil Field Machinery, vol. 44, no. 10, pp. 11-15, 2015.

[11] D. J. Hammerlndl, "Movement, forces, and stresses associated with combination tubing string sealed in packers," Journal of Petroleum Technology, vol. 29, no. 2, pp. 195-208, 1977.

[12] J. Tian, C. Wu, Y. Yang et al., "Establishment and numerical analysis of longitudinal transverse coupled vibration model of downhole drill string," Applied Mathematics and Mechanics, vol. 38, no. 6, pp. 685-695, 2017.

[13] M. Farge and K. Schneider, "Coherent vortex simulation, a semi-deterministic turbulence model using wavelets," Flow, Turbulence and Combustion, vol. 66, no. 4, pp. 393426, 2001.

[14] X. Liu, T. Li, and Y. W. Rui, "River water and sediment multiscale wavelet transform-based research," Evolution in Geography, vol. 35, no. 2, pp. 211-217, 2015. 
[15] N. Jia, Vibration Reduction Optimization Based on Comfort of Wounded Transportation of 4th Tactic Wheeled Vehicle, Academy of Military Medical Sciences, Shanghai, China, 2017.

[16] A. S. Tijsseling, "Fluid-structure interaction in liquid-filled pipe systems: a review," Journal of Fluids and Structures, vol. 10, no. 2, pp. 109-146, 1996.

[17] B. Yu, X. Yan, and X. Yang, "Dynamic reservoir pressure prediction of depleted reservoir gas storage considering the fractal feature of porous medium," Journal of China University of Petroleum (Natural Science Edition), vol. 434, no. 5, pp. 1017-1022, 2013. 


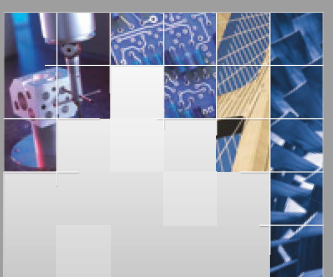

\section{Enfincering}
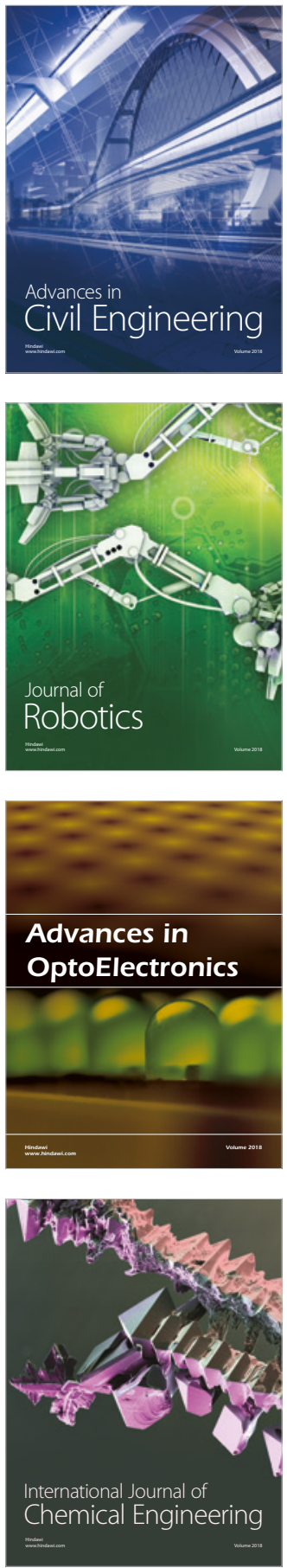

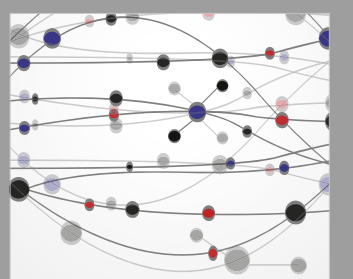

\section{Rotating \\ Machinery}

The Scientific World Journal

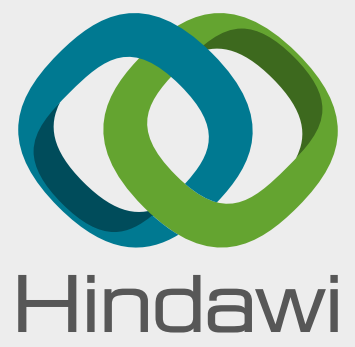

Submit your manuscripts at

www.hindawi.com
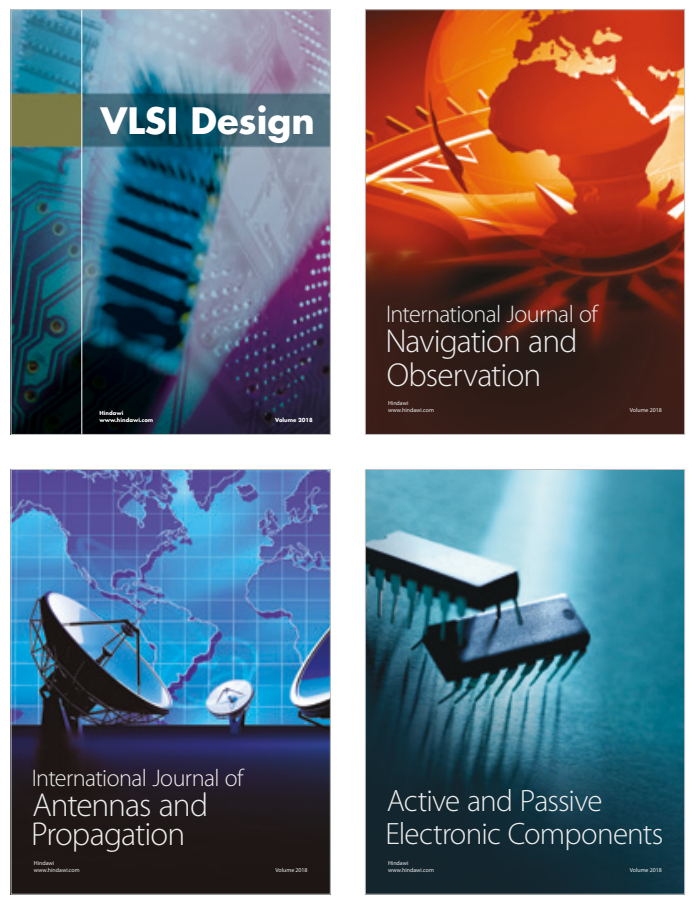
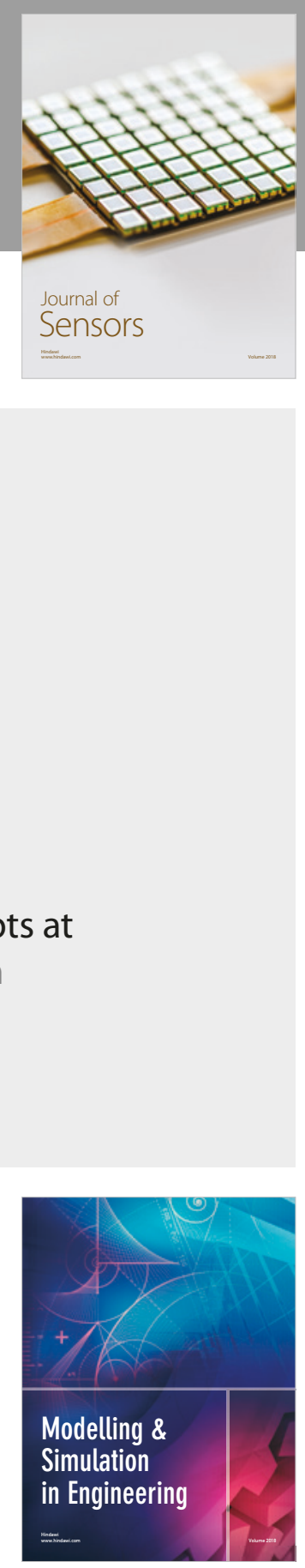

\section{Advances \\ Multimedia}
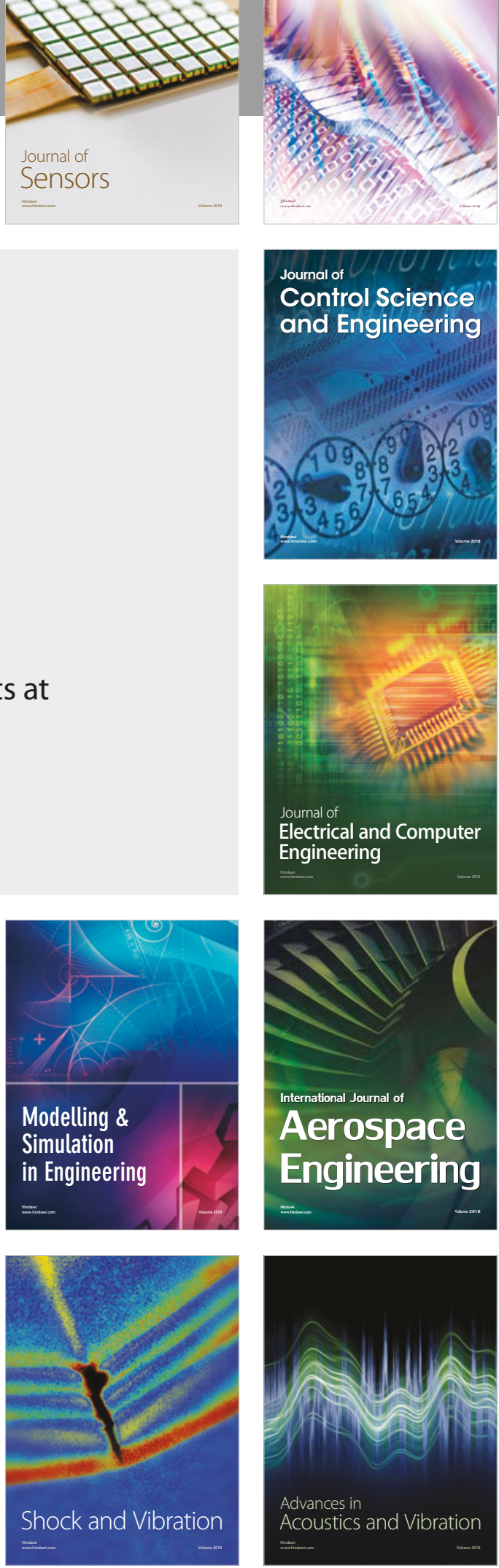